\title{
The association between serum uric acid and blood pressure in different gender in Erbil City
}

\author{
Rundk Ahmad Hwaiz ${ }^{1}$, Mohammed Yousif Merza ${ }^{2}$
}

1 College of Health Sciences, Hawler Medical University

2 College of Pharmacy, Hawler Medical University

Corresponding Author: Rundk Ahmad Hwaiz, Rundk.hwaiz@ hmu.edu.krd

\begin{abstract}
Background and objective: Serum uric acid (SUA) has been known to have a positive association with blood pressure (BP). However, the relationship between SUA and BP in different gender is unclear. In this study, we aimed to investigate the relation of hypertension with hyperuricemia in gender-specific groups.
\end{abstract}

Methods: A total of 350 individuals who underwent serum uric acid and blood pressure examinations at the cardiac center in Erbil city have participated in a cross-sectional study. The result was analyzed to determine the relationship between SUA and BP.

Results: SUA and BP showed a significant relation in the overall population when we evaluated it according to a different gender. Higher hypertension and hyperuricemia prevalence was found in females than in men.

Conclusion: We observed a significantly higher overall prevalence of hyperuricemia and hypertension in women than in men.

Keyword: Hypertension, hyperuricemia, female, Erbil city

\section{INTRODUCTION}

Uric acid is produced during the breakdown of purines, which are found in certain foods and formed by the body. Once produced, uric acid is carried in the blood and passes through the kidneys, where most often is filtered out into the urine. Over recent years there has been renewed debate about the nature of the association between raised serum uric acid concentration and cardiovascular diseases. ${ }^{1}$ Several extensive studies have identified the value of serum uric acid concentration in predicting the risk of cardiovascular events, such as 


\section{Proceeding of the $2^{\text {nd }}$ Scientific Conference on Women's Health \\ 2-3 September 2020 - Hawler Medical University}

myocardial infarction, in populations. It has directed research towards the potential mechanisms by which uric acid might directly or indirectly affect the cardiovascular system. ${ }^{2}$ Increased understanding of these associations' mechanisms may allow a clearer interpretation of the importance of elevated serum uric acid concentrations and the potential value of specific urate-lowering drugs on cardiovascular disease. The prevalence of hypertension is increasing worldwide and is an important contributor to cardiovascular diseases (CVDs) and premature deaths. ${ }^{1,2}$ In the past years, an upward trend of hypertension prevalence has been reported in Iraq. ${ }^{3}$

Hyperuricemia prevalence is increasing rapidly in the world communities; emerging evidence indicates that hyperuricemia is now more common in developing nations and developed nations. ${ }^{4}$ Increased SUA is associated with CVDs, gout, metabolic syndrome, and renal dysfunction. $^{5-8}$ The link between increased SUA and various metabolic syndrome components has been investigated in previous studies. ${ }^{9-11}$ SUA was found to be positively associated with the number of metabolic syndromes, including hypertension. ${ }^{12}$ In recent years, the relationship of SUA with the incidence of hypertension has received widespread attention. An association between increased SUA and hypertension has been reported in some epidemiological studies. ${ }^{13-16}$

It remains unclear whether SUA is a risk factor, a mediator, or merely a marker for hypertension in humans. ${ }^{17} \mathrm{~A}$ few small-scale clinical trials have shown that SUA lowering agents like probenecid and allopurinol can reduce blood pressure in adolescents, ${ }^{18,19}$ suggesting that SUA might be an independent risk factor for hypertension. There are few studies that explored the relationship between SUA levels and hypertension in the general healthy population. To our knowledge, no studies have been conducted to explore the association between SUA and hypertension in different gender in the Kurdistan region of Iraq; therefore, in this study, we aimed to investigate whether elevated SUA level is associated with hypertension in different gender groups in Erbil city. This study may identify a more specific target group in which the association between SUA and BP is the highest, and controlling SUA would have the maximal benefit to control blood pressure, which is a significant risk factor for cardiovascular diseases.

\section{MATERIAL AND METHODS}

A total of 350 subjects who underwent health examinations at (Cardiac Center and Hawler Teaching Hospital) in Erbil city from Nov 2019 to Feb 2020 were enrolled in a cross- 


\section{Proceeding of the $2{ }^{\text {nd }}$ Scientific Conference on Women's Health \\ 2-3 September 2020 - Hawler Medical University}

sectional study. Informed consent was obtained for all of the enrolled patients in our study. To evaluate the relationship between SUA and BP in different gender and ages, we divided the subjects into two groups, male and female (male 180, female 170) samples.

The blood was taken from the vein of the patients and collected inside a biochemical tube. They were transported to the laboratory, and the blood was coagulated then centrifuged for 5 minutes; after that, the serum was separated by using a micropipette, then the level of uric acid was measured by using COBAS c311 machine (Roche Diagnostics GmbH, S and Hofer Strass 116 D-68305 Mannheim, Made in Germany).

\section{Measurement of blood pressure}

Systolic and diastolic BP were measured in all of the subjects. The hypertension diagnosis was based on a systolic BP of $140 \mathrm{mmHg}$ or higher and a diastolic BP of $90 \mathrm{mmHg}$ or higher.

\section{Statistical analysis}

Data were presented as mean values \pm SEM. Statistical evaluations were performed by use of parametrical test (t-test) was performed. $P \leq 0.05$ was considered significant, and n represents the total number of participants in each group. Statistical analysis was performed by use of SigmaPlot 10.0 software (Systat Software, Chicago, IL, USA).

\section{RESULTS}

The serum level of uric acid was found to be significantly higher in hypertensive subjects (7.289 \pm 0.450$)$ as compared with normotensive subjects (4.485 \pm 0.134$)$ (figure1, Table 1).

We determined the level of serum uric acid in hypertensive patients (male and female). Our result shows a significant difference in serum uric acid between hypertensive male and female groups (7.31 \pm 0.55$)$ and $(8.13 \pm 0.80)$, respectively (figure 2). Serum uric acid in hypertensive females was significantly higher than serum uric acid in hypertensive males, $P$ value $=0.035$.

Table 1: Effect of hyperuricemia on blood pressure. Mean value of SUA and standard error of the mean (SEM) for normotensive and hypertensive subjects. $P$-value $<0.05$ considered as significant.

\begin{tabular}{|c|c|c|c|}
\hline & Normotensive & Hypertensive & P-Value \\
\hline Mean value of SUA & 4.485 & 7.289 & \multirow{2}{*}{0.045} \\
\hline SEM & 0.134 & 0.450 & \\
\hline
\end{tabular}




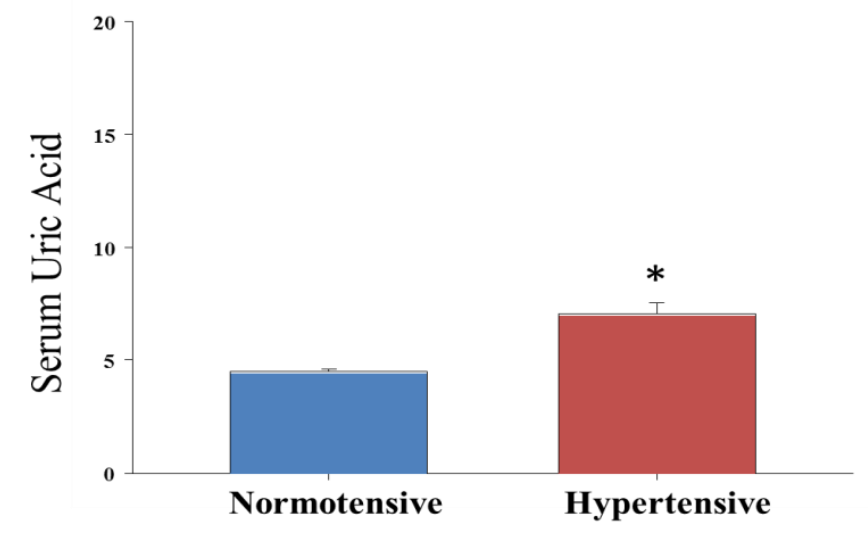

Figure 1: Serum level of uric acid $(\mathrm{mg} / \mathrm{dl})$ in normotensive and hypertensive subjects, $\left(P^{*_{-}}\right.$ value $<0.05$ ), (Normotensive) $n=146$, (Hypertensive) $n=204$.

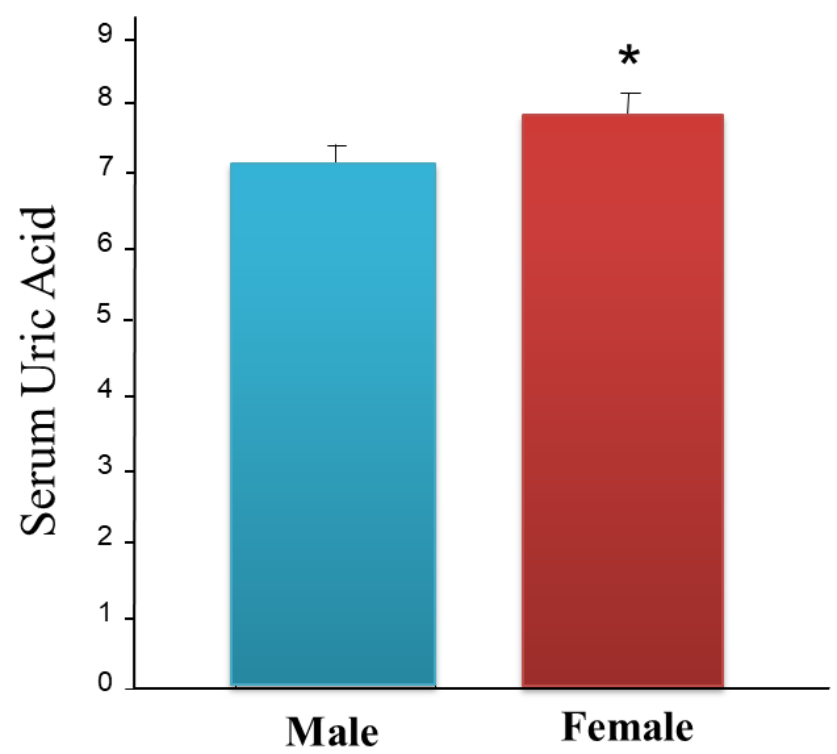

Figure 2: Serum uric acid $(\mathrm{mg} / \mathrm{dl})$ in hypertensive male and female group, $(P$-value $=0.035)$.

The $n($ male $)=70$, and $n($ female $)=96$. 


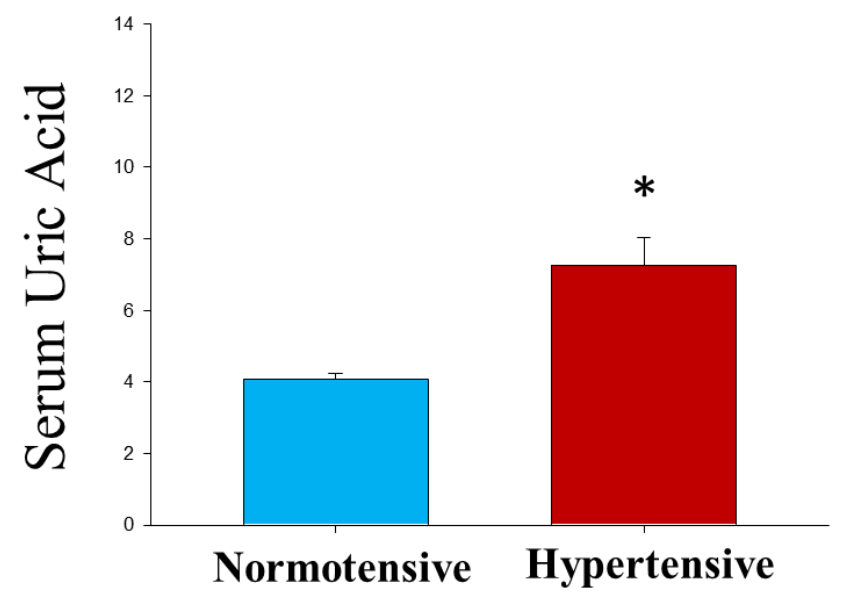

Figure3: Serum uric acid $(\mathrm{mg} / \mathrm{dl})$ in hypertensive female vs normotensive female, $\left(P^{*}\right.$-value $=<0.001)$. The $n($ normotensive female $)=66$ and $n($ hypertensive female $)=104$

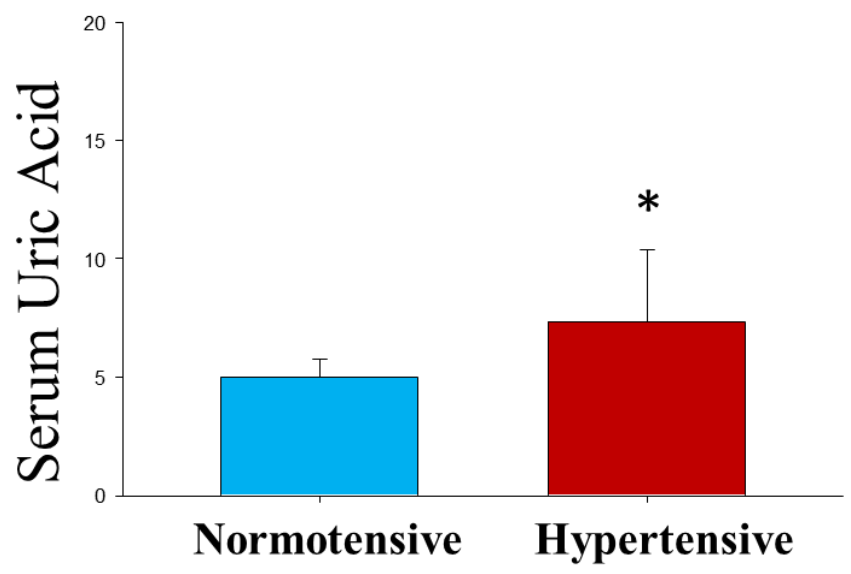

Figure 4: Serum uric acid $(\mathrm{mg} / \mathrm{dl})$ in hypertensive male vs normotensive male, $\left(P^{*}\right.$-value $=$ $<0.001)$. The $n($ normotensive male $)=80$, and $n=($ hypertensive male $)=100$.

The hypertensive female's serum uric acid was significantly higher than the normotensive female (7.23 \pm 0.80$)$ and $(4.056 \pm 0.162)$, respectively (figure 3 ). The serum uric acid in hypertensive males was also significantly higher than the normotensive male $(7.313 \pm 0.552)$ and (4.97 \pm 0.168$)$, respectively (figure 4). In addition, the serum uric acid was significantly higher in females (1.98-fold) than in male subjects (1.27-fold), $P$-value $=0.035$ (figure 2 ).

Hyperuricemia appears to have a more substantial impact on women than men. This trend would be consistent with gender-specific data from other cardiovascular outcomes. For example, a recent meta-analysis of prospective studies using the outcome of coronary artery disease has found that hyperuricemia is more strongly associated with the risk of coronary heart disease outcome in women. ${ }^{15}$ 


\section{Proceeding of the $2^{\text {nd }}$ Scientific Conference on Women's Health \\ 2-3 September 2020 - Hawler Medical University}

\section{DISCUSSION}

The present study's significant findings enable us to identify the importance of gender in the relation between SUA and BP in Erbil city. Although SUA and BP showed a significant link in the overall population, when we evaluated it according to different gender groups (male vs. female), serum uric acid was significantly higher among the hypertensive female population (figures 2, 3, 4). Several studies suggest that the strength of the relationship between SUA and BP among younger age groups and decreases during the aging process as the duration of hypertension gets longer. ${ }^{14,16,18,20}$ However, none of the previous studies have tried to investigate different gender groups' effect on the relationship as a primary goal. To our knowledge, this is the first study to confirm the impact of different gender groups on the relation between SUA and BP in a single cross-sectional survey in the Kurdistan region of Iraq. The prognostic significance of SUA in different disease entities such as diabetes, chronic kidney diseases, and cardiovascular diseases has been recognized in several previous studies. ${ }^{16,21,23}$ Understanding the relationship between each disease and SUA is important due to the potential benefit of applying it to new treatment strategies. Sakata et al. ${ }^{17}$ mentioned that early hypertension developed in children and adolescents with hyperuricemia could be reversed with urate reduction. Hyperuricemia increased the risk of hypertension in both genders compared with control group, and there was a significant difference in women compared with men (figure 2), particularly in women with hyperuricemia. Our study demonstrated a 1.98 fold increase in the risk of hypertension in women compared with males, which increase only 1.27 fold. A stronger association of SUA with BP and hypertension in women was seen, which is in line with previous studies. ${ }^{10,13,16,22}$ Awareness and early interventional strategies in controlling hyperuricemia associated with BP reduction in this specific group may obtain a maximal benefit. To avoid the risk of cardiovascular mortality related to increasing SUA is greater in women than in men.

\section{CONCLUSIONS}

This single cross-sectional study confirmed the relationship between SUA and BP. Hyperuricemia increased the relative risk of hypertension by approximately 1.27 fold in men and by 1.98 fold. We believe that the present study suggests specific gender groups that would obtain maximal benefit from hyperuricemia treatment for the prevention and treatment of hypertension. 


\section{Proceeding of the $2^{\text {nd }}$ Scientific Conference on Women's Health \\ 2-3 September 2020 - Hawler Medical University}

\section{REFERENCES}

1. Alper AB, Jr., Chen W, Yau L, Srinivasan SR, Berenson GS, Hamm LL. Childhood uric acid predicts adult blood pressure: the Bogalusa Heart Study. Hypertension 2005;45:34-8.

2. Alderman M, Aiyer KJ. Uric acid: role in cardiovascular disease and effects of losartan. Current medical research and opinion 2004;20:369-79.

3. Saka M, Shabu S, Shabila N. Prevalence of hypertension and associated risk factors in older adults in Kurdistan, Iraq. Eastern Mediterranean health journal = La revue de sante de la Mediterranee orientale = al-Majallah al-sihhiyah li-sharq al-mutawassit 2020;26:268-75.

4. Ioachimescu AG, Brennan DM, Hoar BM, Hazen SL, Hoogwerf BJ. Serum uric acid is an independent predictor of all-cause mortality in patients at high risk of cardiovascular disease: a preventive cardiology information system (PreCIS) database cohort study. Arthritis and rheumatism 2008;58:623-30.

5. Wertheimer A, Morlock R, Becker MA. A revised estimate of the burden of illness of gout. Current therapeutic research, clinical and experimental 2013;75:1-4.

6. Baker JF, Krishnan E, Chen L, Schumacher HR. Serum uric acid and cardiovascular disease: recent developments, and where do they leave us? The American journal of medicine 2005;118:816-26.

7. Jee SH, Lee SY, Kim MT. Serum uric acid and risk of death from cancer, cardiovascular disease or all causes in men. European journal of cardiovascular prevention and rehabilitation : official journal of the European Society of Cardiology, Working Groups on Epidemiology \& Prevention and Cardiac Rehabilitation and Exercise Physiology 2004;11:185-91.

8. Spaetgens B, Boonen A. The importance of 'state-of-the-art' cost-of-illness studies. Comment on: The economic burden of gout: A systematic review. Seminars in arthritis and rheumatism 2016;45:e9.

9. Iliesiu A, Campeanu A, Dusceac D. Serum uric acid and cardiovascular disease. Maedica 2010;5:186-92.

10. Zhang W, Iso H, Murakami Y, Miura K, Nagai M, Sugiyama D, et al. Serum Uric Acid and Mortality Form Cardiovascular Disease: EPOCH-JAPAN Study. Journal of atherosclerosis and thrombosis 2016;23:1365-6.

11. Okura T, Higaki J, Kurata M, Irita J, Miyoshi K, Yamazaki T, et al. Elevated serum uric acid is an independent predictor for cardiovascular events in patients with severe coronary artery stenosis: subanalysis of the Japanese Coronary Artery Disease (JCAD) Study. Circulation journal : official journal of the Japanese Circulation Society 2009;73:885-91.

12. Navaneethan SD, Beddhu S. Associations of serum uric acid with cardiovascular events and mortality in moderate chronic kidney disease. Nephrology, dialysis, transplantation : official publication of the European Dialysis and Transplant Association - European Renal Association 2009;24:1260-6.

13. Martinez-Quintana E, Tugores A, Rodriguez-Gonzalez F. Serum uric acid levels and cardiovascular disease: the Gordian knot. Journal of thoracic disease 2016;8:E1462-E6.

14. Sabio JM, Vargas-Hitos JA, Mediavilla JD, Navarrete-Navarrete N, Zamora-Posadas M, Perez-Vicente $\mathrm{S}$, et al. Correlation of asymptomatic hyperuricaemia and serum uric acid 


\section{Proceeding of the $2{ }^{\text {nd }}$ Scientific Conference on Women's Health 2-3 September 2020 - Hawler Medical University}

levels with arterial stiffness in women with systemic lupus erythematosus without clinically evident atherosclerotic cardiovascular disease. Lupus 2010;19:591-8.

15. Wang R, Song Y, Yan Y, Ding Z. Elevated serum uric acid and risk of cardiovascular or all-cause mortality in people with suspected or definite coronary artery disease: A metaanalysis. Atherosclerosis 2016;254:193-9.

16. Wu AH, Gladden JD, Ahmed M, Ahmed A, Filippatos G. Relation of serum uric acid to cardiovascular disease. International journal of cardiology 2016;213:4-7.

17. Sakata K, Hashimoto T, Ueshima H, Okayama A, Group NDR. Absence of an association between serum uric acid and mortality from cardiovascular disease: NIPPON DATA 80, 1980-1994. National Integrated Projects for Prospective Observation of Non-communicable Diseases and its Trend in the Aged. European journal of epidemiology 2001;17:461-8.

18. Panoulas VF, Milionis HJ, Douglas KM, Nightingale P, Kita MD, Klocke R, et al. Association of serum uric acid with cardiovascular disease in rheumatoid arthritis. Rheumatology 2007;46:1466-70.

19. Tian Y, Chen K, Xie Z, Fang Y, Wang H, Nie Y, et al. The association between serum uric acid levels, metabolic syndrome and cardiovascular disease in middle aged and elderly Chinese: results from the DYSlipidemia International Study. BMC cardiovascular disorders 2015;15:66.

20. Qin L, Yang Z, Gu H, Lu S, Shi Q, Xing Y, et al. Association between serum uric acid levels and cardiovascular disease in middle-aged and elderly Chinese individuals. BMC cardiovascular disorders 2014;14:26.

21. Li NF, Wang HM, Yang J, Zhou L, Yao XG, Hong J. Serum uric acid is associated with metabolic risk factors for cardiovascular disease in the Uygur population. Applied physiology, nutrition, and metabolism = Physiologie appliquee, nutrition et metabolisme 2009;34:1032-9.

22. Lippi G, Montagnana M, Franchini M, Favaloro EJ, Targher G. The paradoxical relationship between serum uric acid and cardiovascular disease. Clinica chimica acta; international journal of clinical chemistry 2008;392:1-7.

23. Ren Y, Jin N, Hong T, Mu Y, Guo L, Ji Q, et al. Interactive effect of serum uric acid and total bilirubin for cardiovascular disease in Chinese patients with type 2 diabetes. Scientific reports 2016;6:36437. 